\title{
Need to Recognize Efforts From Developing Countries
}

\author{
Bhushan Patwardhan (1D
}

Received: 12 August 2015 / Accepted: 18 December 2015 /Published online: 5 January 2016

(C) Journal of Bioethical Inquiry Pty Ltd. 2015

I read with great interest the article (although now retracted) "Imperialism in Bioethics: How Policies of Profit Negate Engagement of Developing World Bioethicists and Undermine Global Bioethics" (Chattopadhyay, Myser, and De Vries 2015). Publishing this article as an editorial ensured its free access. While I appreciate the decision of the journal editors and publishers to retract this article because of a few errors in statements and data presented, I agree with the central thesis regarding how bioethics gatekeepers from the developed world treat bioethics workers from the developing world, which actually compromises global bioethics. Restricting knowledge through expensive access that is unaffordable for many in the developing world is an issue of great concern in almost all disciplines. The authors' analysis of fourteen journals, even with the errors, provided a picture of exclusionary practices and the hegemony of mighty publishers. Such publishers are now global in operations, but controls surely still reside within the wealthier countries from where the entities hail. So I congratulate the authors for raising the question of the "ethics of bioethics" and highlighting the need for creative solutions to remedy such social injustice.

\footnotetext{
B. Patwardhan $(\bowtie)$

Interdisciplinary School of Health Sciences, Savitribai Phule Pune University, Pune 411007, India

e-mail: bpatwardhan@gmail.com
}

However, I was really disappointed to note that the authors preferred not to mention efforts from developing countries like India. For instance, the Forum for Medical Ethics Society has published the Indian Journal of Medical Ethics since 1993 in an openaccess model. It requires selfless commitment to sustain such effort without any support from governmental or business organizations. Of course, the authors might have had their own reasons to have restricted the article's focus and not include journals published from developed countries. Perhaps the inclusion of journals from developing countries would have required more time and investigation. However, this article highlights how the engagement of developing world bioethicists is being compromised by profit motives. This article also suggests the need for creative solutions to overcome the hegemony and social injustice. Therefore, I feel that reference to creative initiatives like the Indian Journal of Medical Ethics as an example would have further enriched this article. In addition, it would have given due recognition and tribute to selfless, dedicated, and consistent efforts of this Indian forum, which is active in neglected area like bioethics.

\section{References}

Chattopadhyay, S., C. Myser, and R. De Vries. 2015. RETRACTED ARTICLE: Imperialism in bioethics: How policies of profit negate engagement of developing world bioethicists and undermine global bioethics. Journal of Bioethical Inquiry, July 22. doi:10.1007/s11673-015-9654-4. 